\title{
Formation of Multi-Branched Graft Copolymer by Coupling Reaction
}

\author{
Koji Ishizu, Takashi Fukutomi, and Toshio KakuraI \\ Tokyo Institute of Technology, Ookayama, Meguro-ku, Tokyo, Japan.
}

(Received September 2, 1974)

\begin{abstract}
Chloromethylated polystyrene was reacted with polystyryl anion at $-78^{\circ} \mathrm{C}$ and at $20^{\circ} \mathrm{C}$ in mixed solvents (good solvent (tetrahydrofuran (THF)-poor solvent (methylcyclohexane)) and in THF. The decrease in the concentration of the living end was measured photometrically by using a reaction apparatus equipped with an optical cell able to work at low temperatures. The coupling reactions at $-78^{\circ} \mathrm{C}$ ceased within about $15 \mathrm{~min}$. However, the number of branches per backbone polymer molecule increased slightly for all times longer than about $20 \mathrm{~min}$ at $20^{\circ} \mathrm{C}$. One explanation of our results is that the pendant groups were hindered by the grafted polymer chain and the subsequent grafting of the living polymer onto the coupling agent occurred less readily or not at all in some cases, especially when the molecular weight of the polystyryl anion was large and the content of the poor solvent in the reaction mixture was high.
\end{abstract}

KEY WORDS: Chloromethylated Polystyrene / Polystyryl anion / Coupling Reaction / Pendant Group / Grafted Polymer Chain / Molecular Weight / Poor Solvent /

In a previous paper, ${ }^{1}$ we dealt with the formation of a backbone and a single branched chain (1:1-graft copolymer) by the coupling reaction between PMMA and poly $(\alpha$-methylstyryl) anion. We concluded that the structure of $1: 1$-graft copolymer was suffered changes by the reaction conditions: i.e., the ratio of good solvent (THF) to poor solvent (methylcyclohexane), even when the same degree of polymerization (DP) of PMMA and poly $(\alpha$-methylstyryl) anion were used. Our results have shown that all pendant groups of the backbone polymer were not reacted with equal probability under various reaction conditions even at the initial stage of this reaction.

In the present paper, we describe an investigation of the formation of a multi-branched graft copolymer by the coupling reaction of polystyryl anion with chloromethylated polystyrene. Several factors are considered to be important in determining the extent of reaction between the pendant groups on a polymer chain and a reactive group on the end of a polymer chain and these factors are of no significance for a similar reaction between the pendant groups and a low-molecular-weight reagent. One of these factors is the hindering effect of the polymer chain.

\section{EXPERIMENTAL}

Altares, et al. ${ }^{2}$ and Pannell ${ }^{3}$ have reported the reaction of living polymer with chloromethylated polystyrene. According to their results, the comb-shaped polystyrene was obtained in this reaction. It was often suggested that if the lithium salt of styryl anion was used as the initiator, various side reactions would occur in the coupling reaction between the chloromethyl group and styryl anion, resulting in the crosslinking between parent polymers. ${ }^{2,4}$ However, it was also claimed ${ }^{5}$ that such side reactions were negligible if potassium salt was used instead of lithium salt. The polystyrene was chloromethylated $^{6}$ with chloromethyl methyl ether using stannic chloride as a catalyst. The parent polymer was prepared by polymerization of styrene monomer with cumyl potassium in THF. The molecular weight of the parent polymer determined by viscometric measurement was $3.52 \times 10^{4}$. The chlorine content of the chloromethylated polystyrene was $7.5 \%$. The determination of the chlorine content was carried out by Volhard's method. ${ }^{7}$ That is to say, the chloromethylated polystyrene was reacted with a large excess of sodium naphthalene in THF. 
The produced $\mathrm{NaCl}$ salts were titrated by using Volhard's method. The number of chloromethyl functions per backbone polymer molecule was about 85 . The number-average molecular weight of the chloromethylated polystyrene was determined by osmotic pressure measurement in benzene at $37^{\circ} \mathrm{C}$ to be $3.92 \times 10^{4}$. These results show that Volhard's method is one useful measurement for determining the chlorine content. Polystyryl anion was prepared by polymerization of styrene monomer with cumyl potassium in THF. The characteristic absorption maximum of polystyryl anion initiated by cumyl potassium appears at $346 \mathrm{~nm} .{ }^{8}$ Therefore, the change in the concentration of the living end can be observed photometrically. The usual cell could not be used in this reaction, because of the frost which covered the surface of the cell at low temperatures. Figure 1 shows this reaction apparatus. The use of mirrors is considered to be the novel feature of this apparatus. $\mathrm{A}$ is sealed under high vacuum and the tube plated with chromium is fixed within the glass (part A). Therefore, the light passes efficiently through this tube and part of the cell was not covered by frost, even when B was maintained at low temperature $\left(-78^{\circ} \mathrm{C}\right)$. Pyrex glass was

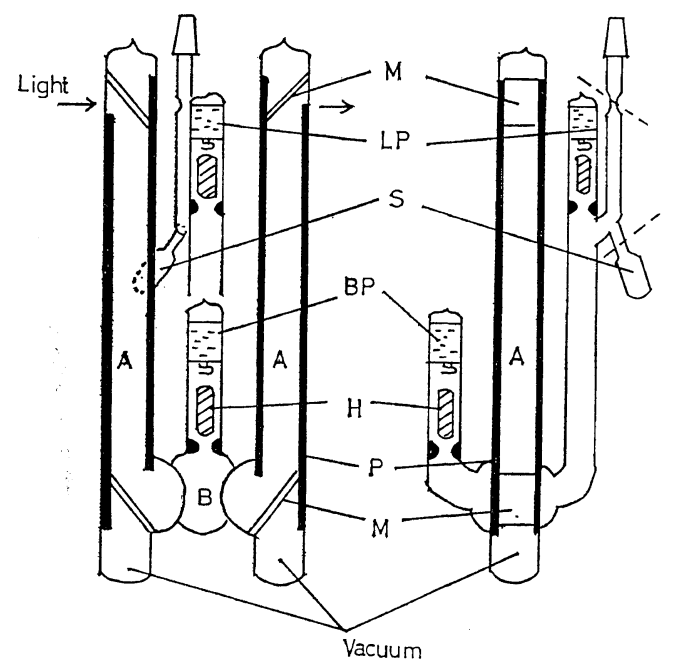

Figure 1. Reaction apparatus to measure the change of the concentration of polystyryl anion: LP, solution of polystyryl anion; BP, solution of backbone polymer; $\mathrm{H}$, magnet coated with glass; $\mathrm{M}$, mirror; $\mathrm{P}$, tube plated with chromium; $\mathrm{S}$, flask. used in this apparatus. The measurement procedure was as follows.

First of all, the pressure in the system was reduced to $10^{-5} \mathrm{mmHg}$. Then purified THF was distilled into the reaction vessel (B) and the whole apparatus was sealed off. After a blank measurement was carried out with THF as solvent, THF was distilled to the flask (S) and this flask was sealed off. The solution of polystyryl anion (LP) was introduced into the reaction vessel (B) by breaking the seal. The apparatus was kept at $-78^{\circ} \mathrm{C}$ for about $2 \mathrm{hr}$ and the solution of a backbone polymer (BP) was introduced into the reaction vessel (B). The light beam passing through the reaction vessel (B) was recorded using the transmittance as a function of the time (Hitachi Model 139 UV-VIS Spectrophotometer). Using Beer's law, the concentrations of polytyryl anion could be calculated. Gel-permeation data of the products were obtained on a Waters Model 200 GPC instrument. Measurements were made using distilled THF at $50^{\circ} \mathrm{C}$ with a three-column system $\left(10^{7}, 10^{6}\right.$, and $\left.10^{5} \AA\right)$ having a flow rate of $1 \mathrm{~m} l / \mathrm{min} . \quad 2 \mathrm{ml}$ of a sample $(0.25 \mathrm{~g} / \mathrm{d} l)$ were injected for $90 \mathrm{sec}$. Then the products were fractionated in a 1-\% benzene solution by Sephadex LH-20, in order to separate linear polystyrene from the mixture. Fractions were poured into methanol and dried in vacuo. The fraction $\left(\mathrm{PSF}_{1}\right)$ was recognized to be the graft copolymer from the gel-permeation datum. In the present work, the number of branches per backbone polymer molecule was computed from the number-average molecular weight of branched polystyrene from osmotic pressure measurements in benzene at $37^{\circ} \mathrm{C}$ using a Mechrolab Model 501 Membrane Osmometer. And the number of branches per backbone polymer melecule calculated from the concentration of the deactivated polystyryl anion was compared with that computed from the osmotic pressure measurements, on the assumption that coupling between the living polymer and chloromethylated backbone had taken place as expected.

\section{RESULTS AND DISCUSSION}

Figure 2 shows the concentration of polystyryl anion as a function of the reaction time for the 


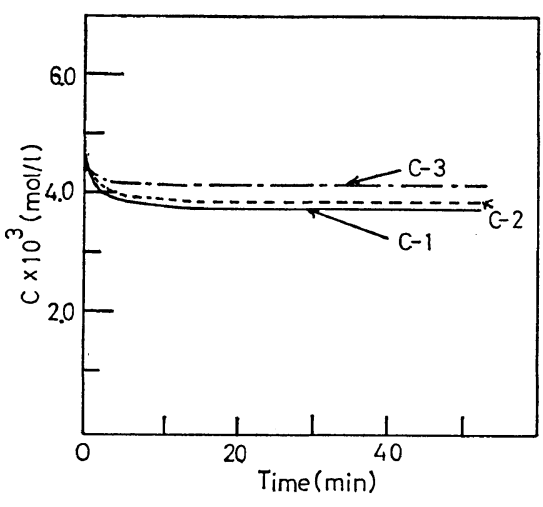

Figure 2. The concentration of polystyryl anions as a function of the reaction time: $\mathrm{C}-1,(-)$; C-2, (----); C-3, (-- -).

reactions C-1, C-2, and C-3. These coupling reactions were carried out by varying only the content of methylcyclohexane in the mixed solvents at $-78^{\circ} \mathrm{C}$. Concentrations of both the backbone polymer and the polystyryl anion for C-1, C-2, and C-3 were kept almost constant (see Table I). Conversion curves show the same phenomenon: the coupling reactions were completed within about $15 \mathrm{~min}$, in spite of the presence of sufficient unreacted functional groups (chloromethyl group and carbanion). As the content of methylcyclohexane in mixed solvents increases, it appears from our results that the concentration of polystyryl anion in the final state (after $50 \mathrm{~min}$ ) increases. Figure 3 a shows GPC profiles of the initial chloromethylated polystyrene, and of the products. It can be seen that the elution peak of each product shifts to the right in comparison with the initial

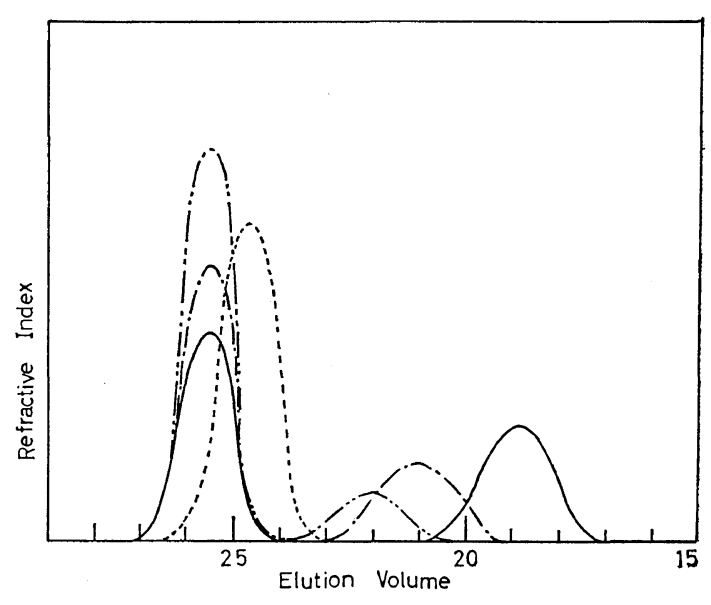

Figure $3(\mathbf{a})$. GPC of the products and chloromethylated polystyrene: C-1, (-); C-2, (---); C-3, (---); chloromethylated polystyrene, (---).

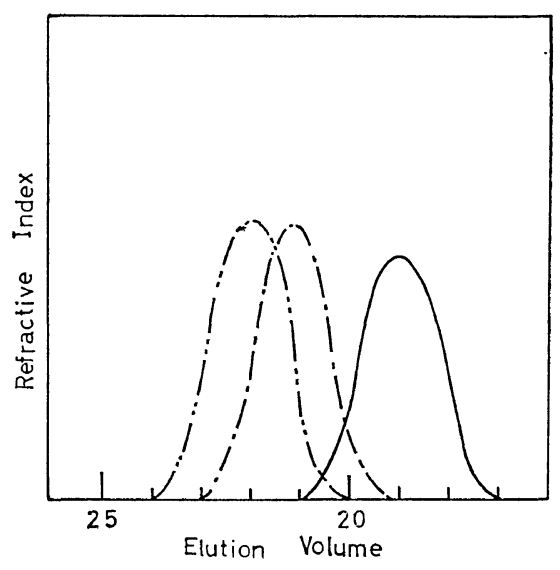

Figure 3(b). GPC of PSF $_{1}$ : C-1, (-); C-2, $(--) ; \mathrm{C}-3,(-\cdots)$.

Table I. Reaction conditions of coupling reactions of polystyryl anion with chloromethylated polystyrene, varying the content of methylcyclohexane in mixed solvents ${ }^{\mathrm{a}}$

\begin{tabular}{lcccc}
\hline No. & $\begin{array}{c}\text { Polystyryl anion } \\
\text { Concn, mol } / l\end{array}$ & $\begin{array}{c}\text { Coupling agent } \\
\text { Concn, mol } / l\end{array}$ & $\begin{array}{c}\text { MCH, } \\
\text { (volume) }\end{array}$ & $\begin{array}{c}\text { Polystyryl anion in the final state } \\
\text { Concn, mol } / l\end{array}$ \\
\hline C-1 & $4.524 \times 10^{-3}$ & $6.436 \times 10^{-3}$ & 0 & $3.752 \times 10^{-3}$ \\
C-2 & $4.369 \times 10^{-3}$ & $6.280 \times 10^{-3}$ & 13.6 & $3.889 \times 10^{-3}$ \\
C-3 & $4.360 \times 10^{-3}$ & $6.189 \times 10^{-3}$ & 23.1 & $4.134 \times 10^{-3}$ \\
\hline
\end{tabular}

a Reaction temp, $-78^{\circ} \mathrm{C}$.

b $M_{w}\left(2.05 \times 10^{4}\right)$ was calculated from viscometric measurements; $M_{w}=1.7 \times 10^{5}[\eta]^{1.35}$ in toluene at $30^{\circ} \mathrm{C} .{ }^{9}$

c $M_{n}, 3.92 \times 10^{4}$.

d $\mathrm{MCH}$, methylcyclohexane.

- By photometrical measurement after $50 \mathrm{~min}$. 
chloromethylated polystyrene. Therefore, each product was recognized to be a mixture of the graft copolymer and of homopolystyrene. Then the products were fractionated by Sephadex LH-20 in a 1-\% benzene solution. Figure $3 \mathrm{~b}$ shows the GPC profiles of the fractions $\left(\mathrm{PSF}_{1}\right)$. By GPC, the molecular weight distribution of $\mathrm{PSF}_{1}$ was identical to that of the graft copolymer (branched polystyrene). The numberaverage molecular weight of $\mathrm{PSF}_{1}$ was determined by osmometry in benzene. The numbers of branches per backbone polymer molecule in the final state of reactions computed from osmometry and photometrical measurement are summarized in Table IV. The values computed from photometrical measurements almost coincided with those from osmometry. The main reasons for the tendencies shown in Figure 2 and Figures $3 \mathrm{a}, \mathrm{b}$ are considered to be the following.

The effect of the solvent composition may be attributed to the different reactivities of free ions, solvent-separated ion pairs, and contact ion pairs. As the content of methylcyclohexane in the mixed solvents increases, the number of free ions in the reaction system becomes smaller. Therefore, the reactivity of the living ends is low in the case of C-3. On the other hand, the steric factors are important in determining the extent of coupling. Methylcyclohexane is a poor solvent for chloromethylated polystyrene and for polystyrene. When the content of methylcyclohexane in mixed solvents increases, the dimensions of the polymer in solution become smaller. ${ }^{1}$ Therefore, the pendant groups are hindered by the grafted polymer chain to an appreciable extent and subsequent grafting of the living polymer on chloromethyl functions occurrs less readily or not at all. The elucidation of both effects described above is the subject for a future study. The details of these points will be described later.

Some coupling reactions were carried out in which only the molecular weight of polystyryl anion was changed. Table II shows reaction conditions; the results obtained are shown in Figure 4 and Table IV. In this case, the coupling reactions also were completed within about $15 \mathrm{~min}$, and the number of branches per backbone polymer molecule decreased, as the molecular weight of polystyryl anion became higher. The hindering was also noticably affected by the increase of molecular weight of the side chains. All these coupling reactions which showed hindering effects were carried out at $-78^{\circ} \mathrm{C}$. These results suggest that the reaction temperature is one of the important factors in

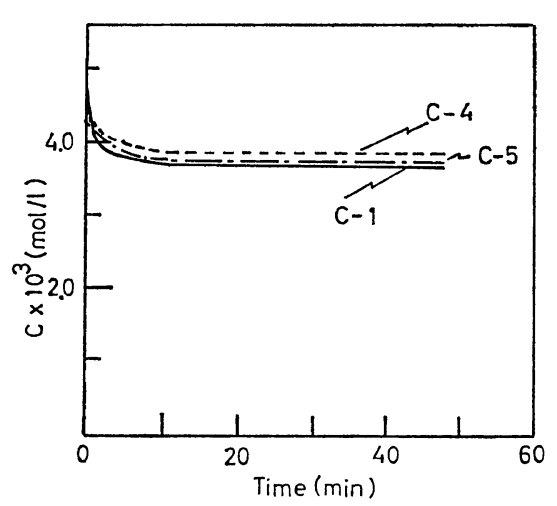

Figure 4. The concentration of polystyryl anions as a function of the reaction time: $\mathrm{C}-1$, ( $(-)$; C-4, (----); C-5, (---).

Table II. Reaction conditions of coupling reactions of polystyryl anion with chloromethylated polystyrene, changing the molecular weight of polystyryl anion ${ }^{a}$

\begin{tabular}{|c|c|c|c|c|}
\hline \multirow{2}{*}{ No. } & \multicolumn{2}{|c|}{ Polystyryl anion } & \multirow{2}{*}{$\begin{array}{l}\text { Coupling agent } \\
\text { Concn, } \mathrm{mol} / l\end{array}$} & \multirow{2}{*}{$\begin{array}{l}\text { Polystyryl anion in the final state } \\
\text { Concn, } \mathrm{mol} / l\end{array}$} \\
\hline & $M_{w}$ & Concn, $\mathrm{mol} / l$ & & \\
\hline C-1 & $2.05 \times 10^{4}$ & $4.524 \times 10^{-3}$ & $6.436 \times 10^{-3}$ & $3.752 \times 10^{-3}$ \\
\hline $\mathrm{C}-4$ & $4.82 \times 10^{4}$ & $4.352 \times 10^{-3}$ & $6.446 \times 10^{-3}$ & $3.783 \times 10^{-3}$ \\
\hline $\mathrm{C}-5$ & $7.69 \times 10^{4}$ & $4.210 \times 10^{-3}$ & $6.408 \times 10^{-3}$ & $3.765 \times 10^{-3}$ \\
\hline
\end{tabular}

a Solvent, THF; reaction temp, $-78^{\circ} \mathrm{C}$.

b $M_{n}, 3.92 \times 10^{4}$.

c By photometrical measurement after $50 \mathrm{~min}$. 
Table III. Reaction conditions of coupling reactions of polystyryl anion with chloromethylated polystyrene, varying the reaction temperature ${ }^{a}$

\begin{tabular}{lcccc}
\hline No. & $\begin{array}{c}\text { Polystyryl anion } \\
\text { Concn, mol } / l\end{array}$ & $\begin{array}{c}\text { Coupling agentc } \\
\text { Concn, mol } / l\end{array}$ & $\begin{array}{c}\text { Reaction temp } \\
{ }^{\circ} \mathrm{C}\end{array}$ & $\begin{array}{c}\text { Polystyryl anion in the final state } \\
\text { Concn, mol } / l\end{array}$ \\
\hline C-6 & $4.550 \times 10^{-3}$ & $4.302 \times 10^{-3}$ & $-78-20$ & $4.014-3.852 \times 10^{-3}$ \\
C-7 & $4.531 \times 10^{-3}$ & $4.086 \times 10^{-3}$ & 20 & $3.805 \times 10^{-3}$ \\
\hline
\end{tabular}

a Solvent, THF.

b $M_{w}, 1.48 \times 10^{4}$.

c $M_{n}, 3.92 \times 10^{4}$.

d By photometrical measurement.

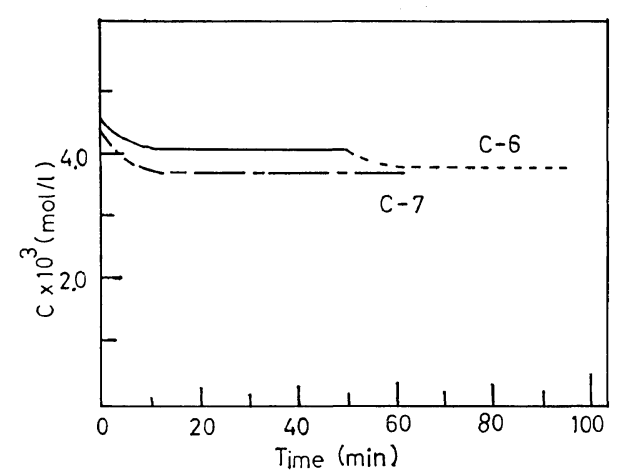

Figure 5. The concentration of polystyryl anions as a function of the reaction time: C-6, (--) ; C-7, (---).

Table IV. Summary of branched polystyrene $\left(\mathrm{PSF}_{1}\right)$

\begin{tabular}{lccc}
\hline & & \multicolumn{2}{c}{$\begin{array}{c}\text { Grafting points (number per } \\
\text { backbone polymer molecule) }\end{array}$} \\
\cline { 3 - 4 } No. & $M_{n}{ }^{\mathrm{a}}$ & $\begin{array}{c}\text { Photometrical } \\
\text { measurement }\end{array}$ & Osmometry \\
\hline C-1 & $2.36 \times 10^{5}$ & 10.2 & 9.6 \\
C-2 & $1.46 \times 10^{5}$ & 6.5 & 5.2 \\
C-3 & $1.11 \times 10^{5}$ & 3.1 & 3.5 \\
C-4 & $3.76 \times 10^{5}$ & 7.5 & 7.0 \\
C-5 & $4.47 \times 10^{5}$ & 5.9 & 5.3 \\
C-6 & $2.23 \times 10^{5}$ & $10.6-13.8$ & -12.4 \\
C-7 & $2.35 \times 10^{5}$ & 15.1 & 13.2 \\
\hline
\end{tabular}

a Measured by osmometry in benzene.

hindering effects. Therefore, some coupling reactions were carried out in THF, at various reaction temperatures (see Table III, Figure 5, and Table IV). In Figure 5, C-6 was carried out at $-78^{\circ} \mathrm{C}$ and after about $50 \mathrm{~min}$ the temperature of the reaction mixture was allowed to warm up gradually to $20^{\circ} \mathrm{C}$. The subsequent conversion curve is shown by the dotted line. From these results, it seems that the phenomenon of the saturation in the coupling reaction appeared at $-78^{\circ} \mathrm{C}$, and the extent of coupling increased when the temperature was increased up to $20^{\circ} \mathrm{C}$. The number of branches per backbone polymer molecule increased from 10.6 to 13.8 (see Table IV). On the other hand, C-7 was carried out at $20^{\circ} \mathrm{C}$ from the beginning. After $50 \mathrm{~min}$, the number of branches per backbone polymer molecule was 15.1 (by photometrical measurement). The number of branches per backbone polymer molecule increased slightly for all times longer than about $20 \mathrm{~min}$. The explanation is considered to be as follows.

In general, the flexibility of a polymer chain in solution is increased by raising the reaction temperature. Eventually, the forces acting among chain segments in solution increase at higher temperatures. Then, even when the pendant groups are hindered by the grafted polymer chain to an appreciable extent at high temperatures, the hindered pendant groups are able to move out of the grafted polymer chain because of the vigorous motion of the segments. This consideration can explain well the phenomenon in which the number of branches per backbone polymer molecule increased slightly for all times longer than about $20 \mathrm{~min}$.

On the other hand, the effect of the reaction temperature may be attributed to the equilibrium between different ionic species. Smid, et al., ${ }^{10}$ have found direct evidence for the existence of two kinds of ion pairs from the electronic spectra of fluorenyl carbanion in THF. According to their results, the ions are formed from solventseparated ion pairs at very low temperatures. 
It may be anticipated that the reactivity of solvent-separated ion pairs approaches that of the free ions. From the results of this reference, the reactivities of living ends at high temperatures are not higher than those at low temperatures. Therefore, steric factors are important in determining the extent of coupling.

To make clear the hindering effects occurring in the formation of the graft copolymer, other approaches are considered to be necessary. One of them is to consider the rate constant of each step-wise process analyzed from the observed value of the reaction rate to form a multibranched graft copolymer. The information obtained from these results will be reported in the near future.

\section{REFERENCES}

1. K. Ishizu, T. Fukutomi, T. Kakurai, and T. Noguchi, Polymer J., 4, 105 (1973).

2. T. Altares, Jr., D. P. Wyman, and V. R. Allen, J. Polym. Sci., Part A, 3, 4131 (1965).

3. J. Pannell, Polymer, 12, 558 (1971).

4. D. F. Hoeg and D. I. Lusk, J. Amer. Chem. Soc., 86, 928 (1964).

5. S. Yen, Makromol. Chem., 81, 152 (1965).

6. G. D. Jones, Ind. Eng. Chem., 44, 2686 (1952).

7. G. Iwasaki, "Bunseki kagaku gaisetzu (Introduction to Quantitative Analysis)", Gakujutzutosho, Tokyo, 1963, p 276.

8. R. Asami, M. Levy, and M. Szwarc, J. Chem. Soc., 361 (1962).

9. T. Fujimoto, N. Ozaki, and M. Nagasawa, J. Polym. Sci., Part A, 3, 2259 (1965).

10. T. E. Hogen-Esch and J. Smid, J. Amer. Chem. Soc., 87, 669 (1965). 